\title{
Molecular Detection of Mutated Factor V (Leiden) and Factor XIII in Ischemic Heart Disease
}

\author{
Olfat Shaker*, Ahmed El-Demery**, Mohamed El Nemr*** \\ and Ahmed Desoky**** \\ Biochemistry Department, Faculty of Medicine, Cairo University*, \\ Biochemistry**, Internal Medicine***and Physiology****, Departments, \\ Faculty of Medicine, October 6 University
}

\begin{abstract}
The present work was performed to evaluate the incidence of gene mutation affecting factor V Leiden (FVL) \&factor XIII in cases of myocardial ischemia. Thirty cases of myocardial ischemia as well as ten age and sex matched healthy subjects were included in the study. DNA was extracted from blood samples drawn from all subjects included in the study and was subjected to PCR amplification for factors V (Leiden) and factor XIII genes, using biotinylated specific primers. The PCR products were hybridized using strip containing immobilized allele-specific oligonucliotide probe. The products of hybridization were visualized using striptavidin-alkaline $\mathrm{pH}$ and color substrate. LDL-c was significantly higher in heterozygous factor $V$ leiden The results of the study showed that heterozygous mutations involving factor $V$ Leiden cases were in a positive correlation with $L D L-c$ results and homozygous mutations involving factor XIII cases showed a positive correlation with AST changes. These results gave an idea about the mutational changes involving factors $V$ Leiden and $X I I I$ and may be considered as risk factors for the incidence of myocardial infarction.
\end{abstract}

\section{INTRODUCTION}

Factor V Leiden mutation was detected in $10 \%$ of patients with coronary artery diseases $(\mathrm{CAD})^{(\mathbf{1})}$. The results suggest that FVL may be one of the important risk factors in developing CAD in northeast Turkey. Systematic review of prospective studies was conducted a considering the risk of recurrent venous thromboembolism among heterozygous carriers of FVL mutation. It was found that heterozygosity of FVL associated with increasing risk of recurrent thromboembolism ${ }^{(2) .}$ In addition, the risk is lower with PTM.On the other hand, FXIII is a transglutaminase that is responsible for covalently crosslinking fibrin therapy stabilizing the fibrin clot In addition, FXIII val-34 Leu was claimed to protect against the occurrence of MI and stroke ${ }^{(3)}$. Further, in (2004) it was stated that val 34 Leu FXIII polymorphism is associated with increased activation of thrombosis ${ }^{(4)}$. There is an observed positive relationship between FXIII polymorphisms and ischemic stroke (IS) when assuming an additive model of inheritance effect ${ }^{\text {(5\&). }}$ In addition, IS risk was markedly higher in female smokers who had FVL. No such 
interaction was present in men. It was concluded that there was an important interaction between the common risk factors and the polymorphism (FVII; FXIII) in the development of $\mathrm{MI}^{(7)}$.

Auro et al. ${ }^{(8)}$ detected that the variants in 4 thrombosis genes $(\mathrm{FV}$, ICAM1, PC and THB1) contribute to arterial cardiovascular events in some Finland population. They stated that analyses comprising several genes belonging to the same pathway may reveal cumulative allelic effects. When acting together these gene variants may affect the disease risk more profoundly than do the single predisposing variants. The aim of the present study is to detect different mutations of factor $\mathrm{V}$ Leiden (FVL) and FXIII in patients with ischemic heart disease.

\section{MATERIAL \& METHODS}

This study was carried on 30 patients who had suffered myocardial ischemia. The sex ratio was 8 females to 22 males. Their age range was (57.16 \pm 5.6$)$ years. They were selected from October 6 University Hospital. 10 healthy subjects matched for sex and age were served as controls. The two groups were subjected to full clinical examination, electrocardiogram (ECG), measuring of arterial blood pressure. Serum cholesterol, High density lipoprotein cholesterol (HDL -c), low density lipoprotein cholesterol (LDL-c), prothrombin time, international normalized ratio (INR), serum alanine transaminase (ALT), serum aspartate transaminase (AST) ${ }^{(\mathbf{9})}$ were determined. In addition, serum bilirubin $^{(\mathbf{1 0}),}$ blood urea (11), serum creatinine $^{(\mathbf{1 2}),}$ hemoglobin, serum glucose and blood film preparation for platelet count were performed.

Mutations of factor $\mathrm{V}$ Leiden (FVL) and factor XIII (FXIII) were detected according to the methodology of kit obtained from Vienna Lab diagnostics Gmb $\mathrm{H}$ Vienna, Austria. The procedure included three steps as follows: 1) DNA isolation; 2) PCR amplification using biotinylated primers; 3) hybridization of amplification products to a test strip containing allele-specific oligonucleotide probes immobilized as an array of parallel lines. Bound biotinylated sequences were visualized and detected using streptavidin-alkaline phosphatase and color substrates. The genotype of the sample was determined using the enclosed collector sheet (Vienna Lab Diagnostics $\mathrm{GmbH}$ ).

\section{1) DNA extraction}

$5 \mathrm{ml}$ blood were withdrawn from each subject and collected on EDTA containing tubes. Blood samples were pipetted into a $1.5 \mathrm{ml}$ microtube, $1 \mathrm{ml}$ lysis solution 1 was added and let to stand for $15 \mathrm{~min}$. at room temperature, then centrifuged for $5 \mathrm{~min}$. at 3000 rpm. $1 \mathrm{ml}$ lysis solution 2 was added and centrifuged for $5 \mathrm{~min}$. at 12000 rpm. The supernatant was removed except $50 \mu \mathrm{l}$ of the visible soft pellet. $200 \mu \mathrm{l}$ of GENXTRACT Resin was added to the pellet and vortex for 10 sec. Samples were incubated for 10 $\min$. at $98^{\circ} \mathrm{C}$ and vortex for $10 \mathrm{sec}$, centrifuged for $5 \mathrm{~min}$. at $12000 \mathrm{rpm}$. The resulting supernatant contains DNA template suitable for immediate use of PCR. The quality and quantity of DNA was analyzed by measuring the OD of the extracted DNA at 260 
nm. Isolated DNA samples were stored at $-20^{\circ} \mathrm{C}$ till used for PCR and typing.

\section{2) In vitro amplification:}

Genotyping for FVL and FXIII polymorphism was performed as follows using biotinylated primeres into two reaction tubes for each amplification samples were prepared and placed on ice: 1)15 $\mu \mathrm{l}$ amplification for FVL; 2) $5 \mu$ diluted Taq DNA polymerase; 3) $5 \mu$ INA template.

Primer sequence for FVL is

Forward primer:

GCTTCCTCGCTCACTGAGTC

Reverse primer: CTGGCCTTTTGCTCACATG

PCR product size: 136 (bp), Homo sapiens

Primer sequence for FXIII is

Forward primer:

GCAGTCCTGTCTGGGTCTTC

Reverse primer: CTGAGATGAACCCTGGCATT

PCR product size:

106 (bp), Homo sapiens

Tubes were copped tightly and run the following thermocycling programs:

1. Pre PCR: $94^{\circ} \mathrm{C} / 2 \mathrm{~min}$.

2. Denaturation and thermocycling at $94^{\circ} \mathrm{C} / 15$ sec. annealing at $58^{\circ} \mathrm{C} / 30$ sec. then elongation at $72^{\circ} \mathrm{C} / 30 \mathrm{sec}$. (for 35 cycles).

3. Final extension: $72^{\circ} \mathrm{C} / 3 \mathrm{~min}$.

\section{3) Hybridization:}

Wash solution A, wash solution B, hybridization buffer, DNA template (DNAT) and conjugated buffer were prewarmed to $45^{\circ} \mathrm{C}$.

$20 \mu \mathrm{l}$ DNAT were pipetted into the corresponding drop of DNAT.

$10 \mu \mathrm{l}$ amplification product was added into the same drop. Contents were mixed with a pipette and let to stand for $5 \mathrm{~min}$. $1 \mathrm{ml}$ of hybridization buffer was added into each tube.

4. Stringent wash: $1 \mathrm{ml}$ wash solution A was added and washed 3 times.
5. Color development: $1 \mathrm{ml}$ conjugate solution was added and incubated for $15 \mathrm{~min}$.

One $\mathrm{ml}$ wash solution $\mathrm{B}$ was added and removed 3 times and then 1 $\mathrm{ml}$ color developer was added and incubated for $15 \mathrm{~min}$. at room temp. in dark. hybridized products were added to a test strip containing allele-specific oligonucleotide probes immobilized as an array of parallel lines. Bound biotinylated sequences were detected using streptavidin-alkaline phosphatase and color substrates. The genotype of the sample was determined using the enclosed Collector sheet (Vienna Lab Diagnostics $\mathrm{GmbH}$ ).

Statistical methods

Statistical package of social science (SPSS) version 9.0 was used for analysis of data. Data was summarized as mean, SD and percentage. T-test was used for analysis of quantitative data, while 
Chi square test was used for analysis of qualitative data. One way ANOVA test was done for analysis of more than 2 quantitative data followed by post HOCC test for detection of significance. P-value is considered significant if $<0.05 *$.

\section{RESULTS}

The study was done on 22 male \& 8 female, patients and 6 male to 4 female,control. The prevalence of diabetes mellitus was significantly higher in IH cases. (12/30). FVL was normal (wild) in $28 \mathrm{IH}$ patients $(93.33 \%)$ and $9(90 \%)$ in control group. It was heterozygous in 2 cases only which represented $6.67 \%$ of the studied cases versus 1 case $(10 \%)$ for the controls.there is a decrease in LDL-c of patients who have heterozygous alleles for FVL (87.5mg $\backslash$ dl vs. $102.7 \mathrm{mg} / \mathrm{dl}, \mathrm{P}<0.02$ ).

Concerning FXIII, the laboratory data of the studied patients showed wild type in $50 \%$ of $\mathrm{IH}$ versus $80 \%$ for the accompanied controls. Homozygosity was detected in $6.67 \%$ of the studied samples.

With the exception of AST value, the readings are found to be within the normal levels. Subjects with wild type and/or heterozygous genes have normal values of AST. Meanwhile, homozygous patients have serum level of AST greater than 3.5 times of the normal value (133.0 $\mathrm{U} / \mathrm{L}$ vs. $38.8 \mathrm{U} / \mathrm{L}, \mathrm{P}<0.00001)$.

Table 1: Characteristics of the studied patients and control subjects and the frequencies of the analyzed allele of FXIII and FVL

\begin{tabular}{|c|c|c|c|c|c|}
\hline \multirow{2}{*}{\multicolumn{2}{|c|}{ Variable }} & \multicolumn{2}{|c|}{ Controls $n=10$} & \multicolumn{2}{|c|}{ Patients $n=30$} \\
\hline & & No. & $\%$ & No. & $\%$ \\
\hline \multicolumn{6}{|l|}{ Sex } \\
\hline & Male & 6 & 60 & 22 & 73.3 \\
\hline & Female & 4 & 40 & 8 & 26.7 \\
\hline \multicolumn{6}{|c|}{ Diabetes mellitus } \\
\hline & Negative & 10 & 100 & 18 & 60 \\
\hline & Positive & - & - & 12 & 40 \\
\hline \multicolumn{6}{|l|}{ FXIII } \\
\hline & Wild type & 8 & 80 & 15 & 50 \\
\hline & Heterozygous & 2 & 20 & 13 & 43.33 \\
\hline & Homozygous & - & - & 2 & 6.67 \\
\hline \multicolumn{6}{|l|}{ FVL } \\
\hline & Wild type & 9 & 90 & 28 & 93.33 \\
\hline & Heterozygous & 1 & 10 & 2 & 6.67 \\
\hline
\end{tabular}


Table 2: Comparison between demographic and laboratory data of Ischemic heart patients included in the study in relation to factor XIII

\begin{tabular}{|c|c|c|c|c|}
\hline Variables & $\begin{array}{l}\text { Wild type } \\
\text { Mean } \pm S D \\
N=15\end{array}$ & $\begin{array}{l}\text { Heterozygous } \\
\text { type } \\
\text { Mean } \pm S D \\
N=13\end{array}$ & $\begin{array}{l}\text { Homozygous } \\
\text { type } \\
\text { Mean } \pm S D \\
N=2\end{array}$ & P-value \\
\hline Age of patients(yrs) & $58.3 \pm 6.4$ & $57.7 \pm 6.3$ & $50.5 \pm 13.4$ & 0.3 \\
\hline $\mathrm{Hb}(\mathrm{g} / \mathrm{dl})$ & $13.1 \pm 1.7$ & $14.5 \pm 1.5$ & $14.0 \pm 1.4$ & 0.06 \\
\hline Platelets $\left(10^{3} / \mathrm{UL}\right)$ & $203.4 \pm 28.7$ & $209.9 \pm 33.4$ & $160.0 \pm 0.0$ & 0.1 \\
\hline Cholesterol (mg/dl) & $242.0 \pm 35.8$ & $257.5 \pm 35.3$ & $243.0 \pm 32.5$ & 0.5 \\
\hline Triglyceride (mg/dl) & $192.2 \pm 49.0$ & $179.6 \pm 18.4$ & $210.0 \pm 0.0$ & 0.5 \\
\hline HDL-c $(\mathrm{mg} / \mathrm{dl})$ & $32.0 \pm 5.1$ & $29.5 \pm 6.0$ & $32.0 \pm 4.2$ & 0.5 \\
\hline LDL-c (mg/dl) & $105.1 \pm 12.5$ & $100.2 \pm 12.4$ & $101.0 \pm 11.3$ & 0.6 \\
\hline INR & $1.1 \pm 0.1$ & $1.2 \pm 0.1$ & $1.3 \pm 0.2$ & 0.6 \\
\hline Prothrombin concentration $(\%)$ & $86.5 \pm 11.0$ & $88.7 \pm 8.8$ & $74.0 \pm 9.9$ & 0.2 \\
\hline Prothrombin time (sec) & $15.4 \pm 2.9$ & $16.2 \pm 5.2$ & $16.0 \pm 2.8$ & 0.9 \\
\hline Total billirubin $(\mathrm{mg} / \mathrm{dl})$ & $0.9 \pm 0.2$ & $1.0 \pm 0.2$ & $1.2 \pm 0.1$ & 0.1 \\
\hline AST $(\mathrm{U} / \mathrm{L})$ & $30.2 \pm 15.7^{\mathrm{a}}$ & $34.2 \pm 11.5^{\mathrm{a}}$ & $133.0 \pm 80.6^{b}$ & $0.0001 *$ \\
\hline $\operatorname{ALT}(\mathrm{U} / \mathrm{L})$ & $28.7 \pm 20.1$ & $32.9 \pm 11.4$ & $31.0 \pm 14.1$ & 0.8 \\
\hline Urea (mg/dl) & $34.3 \pm 15.2$ & $35.0 \pm 12.0$ & $35.0 \pm 9.9$ & 1.0 \\
\hline Creatinine $(\mathrm{mg} / \mathrm{dl})$ & $1.1 \pm 0.2$ & $1.1 \pm 0.2$ & $1.1 \pm 0.1$ & 0.9 \\
\hline
\end{tabular}

$P$-value is significant if $<0.05^{*}$

Table 3: Comparison between demographic and laboratory data of Ischemic heart patients included in the study in relation to factor $\mathrm{V}$

\begin{tabular}{l|lll}
\hline Variables & $\begin{array}{l}\text { Wild type } \\
\text { Mean } \pm \text { SD }\end{array}$ & $\begin{array}{l}\text { Heterozygous type } \\
\text { Mean } \pm \mathbf{S D}\end{array}$ & P-value \\
& $\boldsymbol{N}=\mathbf{2 8}$ & $\boldsymbol{N}=\mathbf{2}$ & \\
\hline Age of patients(yrs) & $57.3 \pm 7.0$ & $60.0 \pm 4.2$ & 0.6 \\
$\mathrm{Hb}(\mathrm{g} / \mathrm{dl})$ & $13.7 \pm 1.7$ & $14.5 \pm 0.7$ & 0.5 \\
Platelets $\left(10^{3} / \mathrm{UL}\right)$ & $203.6 \pm 31.0$ & $200.0 \pm 56.6$ & 0.9 \\
Cholesterol (mg/dl) & $248.7 \pm 35.4$ & $250.0 \pm 42.4$ & 0.9 \\
Triglyceride (mg/dl) & $188.5 \pm 38.3$ & $180.0 \pm 14.1$ & 0.8 \\
HDL-c (mg/dl) & $31.1 \pm 5.5$ & $29.0 \pm 8.5$ & 0.6 \\
LDL-c (mg/dl) & $103.8 \pm 11.9$ & $107.5 \pm 3.5$ & $0.02^{*}$ \\
INR & $1.2 \pm 0.1$ & $1.3 \pm 0.1$ & 0.4 \\
Prothrombin concentration $(\%)$ & $86.8 \pm 10.1$ & $85.0 \pm 18.4$ & 0.8 \\
Prothrombin time (sec) & $15.7 \pm 4.1$ & $16.5 \pm 2.1$ & 0.8 \\
Total billirubin (mg/dl) & $1.0 \pm 0.2$ & $0.9 \pm 0.5$ & 0.5 \\
AST (U/L) & $38.8 \pm 33.7$ & $38.5 \pm 3.5$ & 0.9 \\
ALT (U/L) & $31.1 \pm 16.4$ & $25.0 \pm 12.7$ & 0.6 \\
Urea (mg/dl) & $34.9 \pm 13.4$ & $31.0 \pm 14.1$ & 0.7 \\
Creatinine (mg/dl) & $1.1 \pm 0.2$ & $1.1 \pm 0.2$ & 0.9 \\
\hline P-value is significant if $<0.05$ & & &
\end{tabular}


Table 4: Comparison between LDL-c in relation to factor $\mathrm{V}$

\begin{tabular}{l|lll}
\hline Variables & Factor $\boldsymbol{V}$ Wild & $\begin{array}{l}\text { Factor } \boldsymbol{V} \text { Hetero } \\
\text { Mean } \pm \boldsymbol{S D}\end{array}$ & $\boldsymbol{P}$-value \\
& Mean $\pm \boldsymbol{S D}$ & $\boldsymbol{N}=\mathbf{2 7}$ & \\
& $\boldsymbol{N}=\mathbf{2 7}$ & $107.5 \pm 3.5$ & $0.02^{*}$ \\
\hline LDL & $103.8 \pm 11.9$ &
\end{tabular}

P-value is significant if $<0.05$

Table 5: Comparison between AST in relation to factor XIII

\begin{tabular}{l|llll}
\hline Variables & $\begin{array}{l}\text { Factor XIII Wild } \\
\text { Mean } \pm \text { SD }\end{array}$ & $\begin{array}{l}\text { Factor XIII Hetero } \\
\text { Mean } \pm \text { SD }\end{array}$ & $\begin{array}{l}\text { Factor XIII Homo } \\
\text { Mean } \pm \text { SD }\end{array}$ & P -value \\
\hline LDL & $30.2 \pm 15.7^{\mathrm{a}}$ & $34.2 \pm 11.5^{\mathrm{a}}$ & $133.0 \pm 80.6^{\mathrm{b}}$ & $0.0001^{*}$ \\
\hline
\end{tabular}

$P$-value is significant if $<0.05$

Different symbol indicate significance

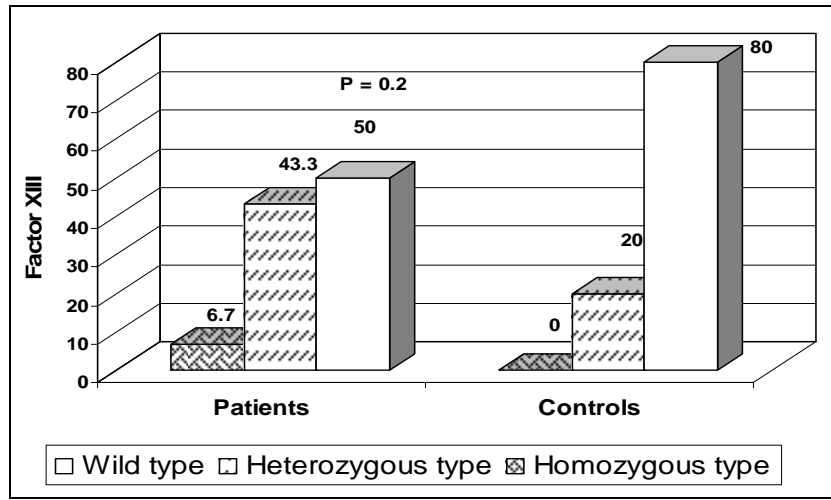

Fig. (1): Comparison between factor XIII in Ischemic heart patients and controls included in the study

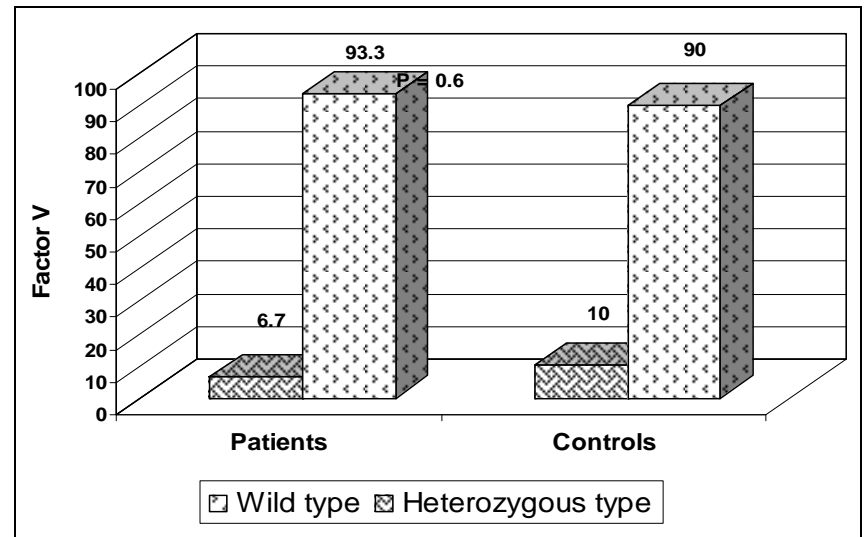

Fig. (2): Comparison between factor $\mathrm{V}$ in Ischemic heart patients and controls included in the study 


\section{DISCUSSION}

The present study was conducted to evaluate the development of ischemic heart diseases.This study included 10 control and 30 patients with history of ischemic heart disease.The present findings are consistent with those recorded by Demirer et al., (13) who observed no association among FVL mutation and metabolic control parameters

The present results pointed to $93.33 \%$ of MI patients with normal phenotype for FVL versus $90 \%$ for the controls. Heterozygous carriers represented $6.7 \%$ of the patients and $10 \%$ for the control subjects.

Our findings agree with Lalouschek et al. (7) (2005) who found that the prevalence of the FVL did not differ significantly between ischemic stroke patients and controlsEmmerich et al. ${ }^{(14) .}$ came to a conclusion that heterozygosity for FVL yields a lifelong hypercoagulable state associated with approximately 5 fold increased risk of venous thrombosis ,the risk is increased with homozygous gene to 50 foldsOn contrast Gurlertop et al., (1) observed FVL mutation in $10 \%$ of coronary arterial diseases (CAD) and were totally absent in control individualsThey suggested that FVL mutation may be one of the important risk factors in developing CAD. This opinion is in concert with that of Endler and Mannhalter (15). who stated that FVL mutation is most common genetic risk factors of venous thrombosis (VTE) On the other hand, Marchiori et al., (2) concluded that in patients with VTE heterozygous carrier of FVL is clearly associated with increased risk of recurrent thrombo-embolism

The present study revealed significant increase in heterozygosity of FVL and LDL-c value compared to wild gene of FVL. This result is in agreement with that of Avellone et al. (16) who detected that patients suffered of MI and activated protein $\mathrm{C}$ resistance displayed significantly higher level of LDL-c It is also run in full agreement with that of Ganong $^{(17) .}$ that LDL plasma concentration correlates positively with myocardial infarction and ischemic stroke Biochemical studies have revealed that FXIII is a key regulator of fibrinolysis and in addition to its role in haemostasis, it has also been implicated in the pathology of arterial and venous thrombosis ${ }^{(18)}$.

The present results revealed that the wild type of FXIII was detected in $50 \%$ of the examined patients and $80 \%$ for the controls. Whereas $43.33 \%$ of patients are heterozygous carriers versus $20 \%$ for the control subjects. Homozygous alleles of FXIII are represented in $6.66 \%$ of the patients. In this respect Catto et al. (1999) stated that homozygosity for FXIII, mutation is associated with increased enzyme activity and heterozygous exhibit intermediate activity when compared with noncarriers $^{(19)}$ FXIII val-34 Leu was claimed to protect against the occurrence of MI and stroke $\left.{ }^{(3}\right)$. It displayed a heterozygous ethnic distribution and a protective effect against venous thrombosis was also proposed ${ }^{(20) .}$

A common polymorphism of the FXII A subunit (FXIII val $34 \mathrm{Leu}$ ) has 
been identified as a protective factor against both arterial and venous thrombosis. Hancer et al. (21) in MI patients study supported the hypothesis that val 34 Leu polymorphism in FXIII gene has a protective effect against MI. Mainly the genotype 34 Leu of FXIII showed significantly protective effect in MI patients (22).

The present data reflected high level of aspartate transaminase (AST) in FXIII homozygous patients. The value was 3.5 times greater than normal. It is well known that liver, kidney, myocardium, haematopoietic tissues erythrocytes are richer in transaminases than other body tissues. Consequently, destruction or necrosis of any of these tissues - as a result of pathological process, hypoxia state in these active cells or environmental factors, lead to release of a large amount of these enzymes into the serum $^{(17,23,24,25 \& 26) \text {. }}$

Finally, it could be concluded that the concept that ischemic heart disease is attributed to genetic and environmental factors interactions, is generally approved. So, further studies are necessary using more patients and analysis of different predisposing variants to know more about the risk factors causing MI.

\section{REFERENCES}

1. Gurlertop, H.Y.; Gundogdu, F.; Pirim, I.; Islamoglu, Y.; Egerci, N.; Sevimli, S.; Erdem, F. and Senocak, H. (2007): Association between facor $\mathrm{V}$ Leiden mutation and coronary aryery disease in the northeast region of Turkey.
Blood Coagul. Fibrinolysis, 18(8): 719-22.

2. Marchiori, A.; Mosena, L.; Prins, M.H. and Prandoni, P. (2007): The risk of recurrent venous thromboembolism among heterozygous carriers of factor $\mathrm{V}$ Leiden or prothrombin G 20210 A mutation. A systematic review of prospective studies. Haematologica, 92(8): 1107-14.

3. Elbaz, A.; Poirier, O.; Canaple, S.; Chedru, E.; Cambien, F. and Amareneo, P. (2000): The association between the Val 34 Leu polymorphism in the factor XIII gene and brain infarction. Blood, 95: 586-591.

4. Kobbervig, C. and Williams, E. (2004): FXIII polymorphism, fibrin clot structure and thrombotic risk. Biophys. Chem., 112(2-3): 223-8.

5. Rubattu, S.; Di Angelantonio, E.; Nitsch, D.,; Gigante, B.; Zand, B.; Stqanzione, R.; Evangelista, A.; Pirisi, A.; Rosati, G. and Volpe, $M$. (2005): Polymorphisms in prothrombotic genes and their impact on ischemic stroke in a Sardinian population. Thromb. Haemost., 93: 1095-100.

6. Pruissen, D.M.; Kappelle, L.J.; Rosendaal, F.R.; Algra, A.; On behal of the SMART Study Group (2008): Prothrombotic genetic variants and atherosclerosis in patients with cerebral ischemia of arterial origin. Atherosclerosis, Sep., 4. (E pub a head of print).

7. Lalouschek, W.; Schilinger, M.; Hsieh, K.; Endler, G.; Tentschert, S.; Lang, W.; 
Chemg, S. and Mannhalter, C. (2005): Matched cqase-control study on factor $\mathrm{V}$ Leiden and the prothrombin G20210A mutation in patients with ischemic stroke/transient ischemic attack up to the age of 60 years. Stroke, 36: 1405-1409.

8. Auro, K.; Alanne, M.; Kristiansson, K.; Silander, K.; Salomaa, V.; Peltonen, L. and Perola, M. (2007): Combined effects of thrombosis pathway gene variants predict cardiovascular events. PLOS Genetics, 3(7): e120. Doi: $10.1371 /$ J. pgen. 0030120 .

9. 9Thomas, L. (1998): Clinical Laboratory Diagnosis. Frankfurt: TH-Books, 1998. 187. Tietz NW. Clinical Guide to Laboratory Tests.

10. Jendrassik, L. Gróf P., Schellong $G$ and Wende; et al. (1938):

Vereinfachtephotometrische Methodenzur The Quality of Diagnostic Biochemistry, pp. 297-82.

11. Patton, C.J. and Crouch, S.R. (1977): Spectrophotometric and kinetics investigation of the Berthelot reaction for the determination of ammonia. Anal. Chem., 49: 464-469.

12. Henry, R.J. (1974): Clinical chemistry, principles and techniques, $2^{\text {nd }}$ edition. Harper and Row, p. 525.

13. Demirer, A.N.; Alikasifaglu, M.; Tuncbilek, E.; Karakus, S. and Erbas, T. (2008): Factor V Leiden mutation and type 1 diabetes mellitus. Blood Coagul. Fibrinolysis, 19(1): 70-4.
14. Emmerich, J.; Rosendaal, F.R.; Cattaneo, M.; et al. (2001): Combined effect of factor $\mathrm{V}$ Leiden and prothrombin 20210A on the risk of venous thromboembolism. Ololed analysis of 8 case-control studied including 2310 cases and 3204 controls. Study Group for Poolked-Analysis in venous thromboembolism. Thromb. Haemost., 86: 809-816.

15. Endler, G. and Mannhalter, C. (2003): Polymorphisms in coagulation factor genes and their impact on arterial and venous thrombosis. Clin. Chim. Acta., 330: 31-55.

16. Avellone, G.; Di Garbo, V.; Di Raimonde, D.; Bono, M.; Abruzzese, G.; De Simone, R. and Raneli, G. (2001): Evaluation of resistance to activated protein $\mathrm{C}$ in myocardial infarction patients. Minerva Cardioangiol.; 49:363-8.

17. Ganong, W.F. (2003): Endocrinology, Metabolism and Reproductive Function. In: Review of Medical Physiology. 21 ed. Lange Medical Books, McGraw-Hill, Egypt, pp. 297 and 310 .

18. Muszbek, L.; Bagoly, Z.; Bereczky, Z. and Katona, E. (2008): The involvement of blood coagulation factor XIII in fibrinolysis and thrombosis. Cardiovasc. Hematol. Agents Med. Chem., 6(3): 190-205.

19. Catto, A.J.; Kohler, H.P.; Coore, J.; Mansfield, M.W.; Stickland, M.H. and Gran, P.J. (1999): Association of a common polymorphism in the factor XIII 
gene with venous thrombosis. Blood, 93: 906-908.

20. Francs, R.F.; Middeldorp, S.; Meinardt, J.R.; van Pampus, E.C. and Rcitsma, P.H. (2000): Factor XIII Val 34 Leu and the risk of venous thromboembolism in factor $\mathrm{V}$ Leiden carriers. Brit. J. Haematol., 111: 118-121.

21. Hancer, V.S.; Diz-Kucukkaya, R.; Bilge, A.K.; Ozben, B.; Oncul, A.; Ergen, G. and Nalcaci, M. (2006): The association between factor XIII Val 34 Leu polymorphism and early myocardial infarction. Circ. J., 70(3): 239-42.

22. Salazar-Sanchez, L.; Chaves, L.; Cartin, M.; Schuster, G.; Wuiff, K.; Schroder, W. and Herrmann, F.H. (2006): Common polymorphisms and cardiovascular factors in patients with myocardial infarction of Costa Rica. Rev. Biol. Trap. (Int. J. Trop. Biol., ISSN-0034-7744) 54(1): 1-11.
23. Fahim, F.A.; Yousri, R.M.; Roushdy, H.M. and Abady, M.I. (1991): Some biochemical aspects of the protective effect of strontium chloride on gamma irradiated rats. Isotopenpraxis, 27(7): 318-324.

24. Mazour, L.; Manowska, J. and Bobik, R. (1991): Effect of ${ }^{60} \mathrm{Co}$ gamma-irradiation of mice on the temporal changes of acid phosphatase activity in spleen and liver. Acta Physiologica Hungaria, 78(2): $135.1^{\text {st }}$ ed, Frankfurt:

25. Abou-Safi, H.M. (1998): Haematological and physiological impairment of irradiation during estrus cycle in rats and role of combined treatment with vitamins A and B group. Egypt. J. M. Sci., 19(1): 157-174.

26. Mohammad, E.T. (2002): Effect of gamma irradiation on some haemostatic process linked to inflammatory reactions. $\mathrm{Ph}$. D. Thesis. Faculty of Science, Ain Shams University.

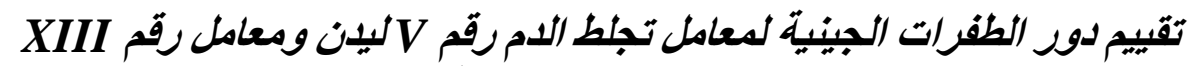

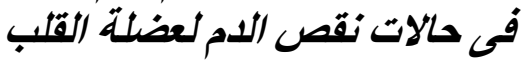

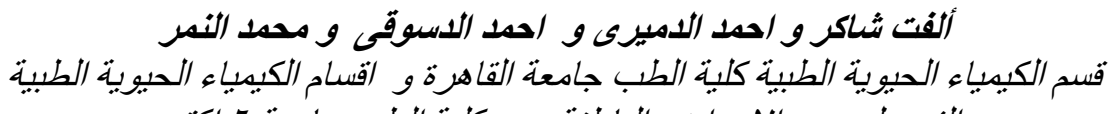

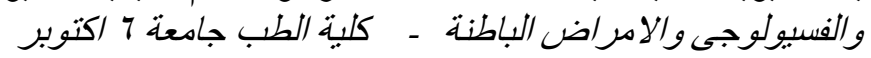

أجريت هذه الدراسة لتقييم دور الطفرات الجينية لمعامل تجلط الدم رقم V ليدن ومعامل رقم XIII في حالات

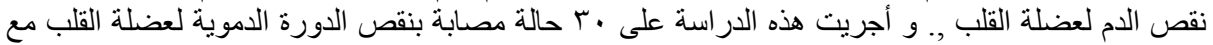

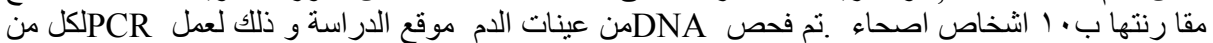

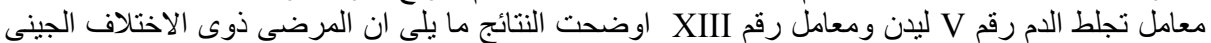

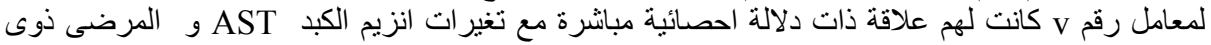

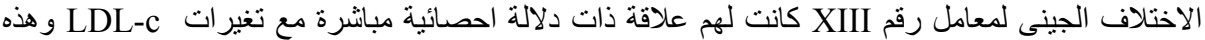

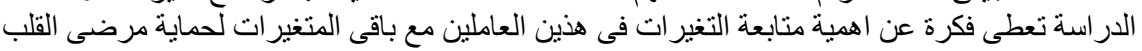

